\title{
Nitrificação do nitrogênio amoniacal de dejetos líquidos de suínos em solo sob sistema de plantio direto
}

\author{
Celso Aita(1), Sandro José Giacomini( ${ }^{(1)}$ e André Paulo Hübner ${ }^{(1)}$
}

(1)Universidade Federal de Santa Maria, Dep. de Solos, Caixa Postal 221, CEP 97105-900 Santa Maria, RS. E-mail: caita@ccr.ufsm.br, sjgiacomini@smail.ufsm.br, andrepaulohubner@yahoo.com.br

\begin{abstract}
Resumo - O objetivo deste trabalho foi avaliar a taxa de nitrificação do $\mathrm{N}$ amoniacal dos dejetos líquidos de suínos, aplicados ao solo em sistema de plantio direto. $\mathrm{O}$ experimento foi realizado durante três anos agrícolas, em um Argissolo Vermelho distrófico arênico. O delineamento experimental foi o de blocos ao acaso, em parcelas subdivididas, com três repetições. As parcelas principais foram compostas por dois sistemas de cultura (aveia $\mathrm{preta} / \mathrm{milho}$ e pousio/milho) e as subparcelas, por doses de dejetos $\left(0,40\right.$ e $80 \mathrm{~m}^{3} \mathrm{ha}^{-1}$ por ano). A nitrificação foi estimada a partir da determinação dos teores de $\mathrm{N}$ mineral em diferentes camadas do solo, em diversas épocas, após a aplicação dos dejetos. Na média dos três anos, a taxa líquida de nitrificação no sistema aveia/milho atingiu $4,8 \mathrm{~kg} \mathrm{ha}^{-1} \mathrm{dia}^{-1}$ de $\mathrm{N}$ na forma de nitrato e superou aquela do sistema pousio/milho em $43 \%$. A aplicação dos dejetos na dose $80 \mathrm{~m}^{3} \mathrm{ha}^{-1}$ resultou em uma taxa de nitrificação superior à verificada na dose de $40 \mathrm{~m}^{3} \mathrm{ha}^{-1} \mathrm{em}^{-}$ $188 \%$. O N amoniacal dos dejetos líquidos de suínos é rapidamente nitrificado no solo em plantio direto e completamente oxidado a N nítrico entre 15 e 20 dias após a aplicação dos dejetos.
\end{abstract}

Termos para indexação: nitrato, mineralização, resíduos culturais.

\section{Nitrification of ammoniacal nitrogen from pig slurry in soil under no-tillage}

\begin{abstract}
The objective of this work was to evaluate the nitrification rate in no-tillaged soil treated with pig slurry. The experiment was carried out during three years in an Arenic Hapludult soil, in a complete randomized block design, with split plots and three replications. The main plots were composed of two crop systems (black oat/maize and fallow/maize) and the split plots were composed of three rates of pig slurry $\left(0,40\right.$ and $\left.80 \mathrm{~m}^{3} \mathrm{ha}^{-1}\right)$. The nitrification was evaluated based on concentrations of mineral $\mathrm{N}$, in different soil layers, in several periods after pig slurry application. On the average of the three years, the nitrification rate in the black oat/maize system reached $4.8 \mathrm{~kg} \mathrm{ha}^{-1}$ of $\mathrm{NO}_{3}^{-}-\mathrm{N}$ per day, overcoming that of the fallow/maize system in $43 \%$. The application of $80 \mathrm{~m}^{3} \mathrm{ha}^{-1}$ of pig slurry resulted in $188 \%$ greater nitrification rate than that observed for $40 \mathrm{~m}^{3} \mathrm{ha}^{-1}$. The ammoniacal $\mathrm{N}$ from pig slurry is rapidly nitrified in soil under no-tillage, being completely oxidized to $\mathrm{NO}_{3}^{-}-\mathrm{N}^{-}$from 15 to 20 days after pig slurry application.
\end{abstract}

Index terms: nitrate, mineralization, crop residues.

\section{Introdução}

Os dejetos de suínos na forma líquida e o seu armazenamento em esterqueiras são as formas predominantes de manejo deste material. Nas esterqueiras, onde o ambiente é essencialmente anaeróbico, ocorre o acúmulo de $\mathrm{N}$ na forma de amônio, uma vez que a oxidação dessa forma de $\mathrm{N}$ até nitrato depende da presença de $\mathrm{O}_{2}$ (Schmidt, 1982). Considerando-se que 40 a $70 \%$ do $\mathrm{N}$ total dos dejetos de suínos encontra-se na forma amoniacal $\left(\mathrm{NH}_{3} \mathrm{e}\right.$ $\mathrm{NH}_{4}{ }^{+}$), quando tais dejetos são aplicados no campo (Scherer et al., 1996), é de fundamental importância, tanto do ponto de vista do seu potencial fertilizante, como também de seu potencial poluente, o estudo das transformações microbianas dessa fração de $\mathrm{N}$ no solo, especialmente a sua taxa de oxidação pela população microbiana de nitrificadores.

A rapidez com que o $\mathrm{N}$ amoniacal dos dejetos é nitrificado, após a sua aplicação no campo, irá condicionar a quantidade de $\mathrm{NO}_{3}{ }^{-}$no solo. Se a taxa de nitrificação for elevada, os teores de $\mathrm{N}$ na forma de nitrato $\left(\mathrm{N}^{-\mathrm{NO}_{3}}{ }^{-}\right)$aumentarão rapidamente, muitas vezes em época em que a demanda de $\mathrm{N}$ pelas culturas ainda é pequena. Dependendo da intensidade e da quantidade de chuvas nesse período, poderão ocorrer perdas 
significativas de $\mathrm{N}$ via lixiviação de $\mathrm{NO}_{3}{ }^{-}$, pois o $\mathrm{N}$ nítrico é solúvel em água e possui baixa energia de ligação com os colóides do solo (Whitehead, 1995), o que contribui para a contaminação das águas superficiais e subsuperficiais. Elevados teores de $\mathrm{NO}_{3}{ }^{-}$no solo também podem resultar em acúmulo desta forma de $\mathrm{N}$ no tecido vegetal, o que pode comprometer a qualidade das plantas para o consumo humano e animal (L'Hirondel \& L'Hirondel, 2002). Além disso, em condições de deficiência de $\mathrm{O}_{2}$, algumas bactérias utilizam o $\mathrm{N}^{-\mathrm{NO}_{3}}{ }^{-}$ como aceptor final de elétrons na cadeia respiratória, reduzindo-o para $\mathrm{N}_{2}$ no processo de desnitrificação (Dendooven et al., 1998). Um dos gases intermediários deste processo é o óxido nitroso $\left(\mathrm{N}_{2} \mathrm{O}\right)$, o qual pode afetar a camada de ozônio, além de contribuir para o aquecimento global (Rochette et al., 2004).

No entanto, se o $\mathrm{N}$ amoniacal dos dejetos de animais for lentamente nitrificado no solo, as perdas de $\mathrm{N}$ por volatilização de amônia podem aumentar, o que resulta em diminuição do potencial fertilizante nitrogenado dos dejetos e contribui para a acidificação de ecossistemas florestais, pela possibilidade de ocorrência de chuva ácida (Morvan, 1999). Essas perdas de $\mathrm{N}$ por volatilização de amônia podem atingir valores entre 20 e $80 \%$ do $\mathrm{N}$ amoniacal adicionado (Morvan, 1999). Portanto, o conhecimento do destino da fração amoniacal dos dejetos de animais, com destaque para a velocidade de nitrificação, é fundamental para a inclusão desses dejetos em programas de adubação das culturas.

A velocidade de nitrificação do $\mathrm{N}$ amoniacal dos dejetos líquidos de suínos, após a sua aplicação no campo, é um aspecto ainda pouco estudado pela pesquisa brasileira. Em outros países, este assunto é estudado com mais intensidade, embora a maioria dos trabalhos seja realizada em laboratório, em condições controladas (Flowers \& O'Callaghan, 1983; Dendooven et al., 1998; Morvan, 1999). Ao trabalhar em três tipos de solo, Morvan (1999) quantificou a nitrificação pela análise periódica dos teores de $\mathrm{N}$ nas formas de amônio $\left(\mathrm{N}-\mathrm{NH}_{4}{ }^{+}\right)$e nitrato $\left(\mathrm{N}-\mathrm{NO}_{3}{ }^{-}\right)$do solo, em um experimento de incubação em laboratório, a $16^{\circ} \mathrm{C}$, em que todo o $\mathrm{N}_{-} \mathrm{NH}_{4}{ }^{+}$, de 30 amostras de dejetos líquidos de suínos, foi completamente oxidado a $\mathrm{N}_{-} \mathrm{NO}_{3}{ }^{-}$em 24 dias. Na primavera/verão, que é a época preferencial para a aplicação de dejetos de suínos na Região Sul do Brasil, é provável que a nitrificação seja ainda mais rápida do que a observada por Morvan (1999), já que as temperaturas médias são superiores a $16^{\circ} \mathrm{C}$.
O processo de nitrificação pode ser avaliado no solo, a partir da variação temporal dos teores de $\mathrm{N}$ mineral, após a adição de quantidades conhecidas de $\mathrm{N}$ amoniacal por meio de fertilizantes minerais ou orgânicos, ou por meio de dejetos de animais. Essa forma de cálculo, utilizada na maioria das situações (Malhi \& McGill, 1982; Flowers \& O'Callaghan, 1983), permite estimar apenas a nitrificação líquida ocorrida no período de tempo considerado. Para se estimar a nitrificação bruta, é necessário utilizar o isótopo ${ }^{15} \mathrm{~N}$, para marcar a fração amoniacal dos dejetos com uma solução de $\mathrm{N}$ amoniacal enriquecida com ${ }^{15} \mathrm{~N}$, e acompanhar o enriquecimento em ${ }^{15} \mathrm{~N}$ no nitrato formado dentro do período de tempo considerado. Embora este método permita determinar a quantidade total de $\mathrm{N}$ amoniacal nitrificado, ele é raramente utilizado (Müller et al., 2003), em razão da necessidade de equipamentos específicos para tal e do custo relativamente elevado das análises.

Com a rápida adoção e expansão das áreas cultivadas no sistema plantio direto (SPD), na Região Sul do Brasil, é cada vez mais comum aplicarem-se dejetos de animais diretamente sobre os resíduos culturais das plantas de cobertura no outono/inverno, antes da semeadura do milho. É provável que a não mobilização do solo e a presença dos resíduos culturais na superfície proporcionem condições de temperatura e umidade mais favoráveis à nitrificação do que no preparo convencional. Em razão da carência de informações de pesquisa, é necessário intensificar os trabalhos nesta área e avaliar a nitrificação em SPD, especialmente com o uso de dejetos líquidos de suínos, cujos teores de $\mathrm{N}$ amoniacal são, normalmente, elevados.

O objetivo deste trabalho foi avaliar a taxa líquida de nitrificação do $\mathrm{N}$ amoniacal dos dejetos líquidos de suínos, aplicados sobre os resíduos culturais do sistema pousio/milho e do sistema aveia preta/milho, em plantio direto.

\section{Material e Métodos}

Este trabalho foi desenvolvido em campo, durante três anos agrícolas (1998/1999, 1999/2000 e 2000/2001), na área experimental do Departamento de Solos, da Universidade Federal de Santa Maria (RS), em um Argissolo Vermelho distrófico arênico (Embrapa, 1999), com textura superficial franco-arenosa no horizonte $\mathrm{Ae}$ franco-argilosa no horizonte B. No início do experimento, o teor de argila do solo da camada $0-20 \mathrm{~cm}$ foi de $150 \mathrm{~g} \mathrm{~kg}^{-1} \mathrm{e}$ o teor de matéria orgânica de $16 \mathrm{~g} \mathrm{~kg}^{-1}$. 
A pluviometria e as temperaturas máximas e mínimas, ocorridas em cada ano, estão mostradas na Figura 1.
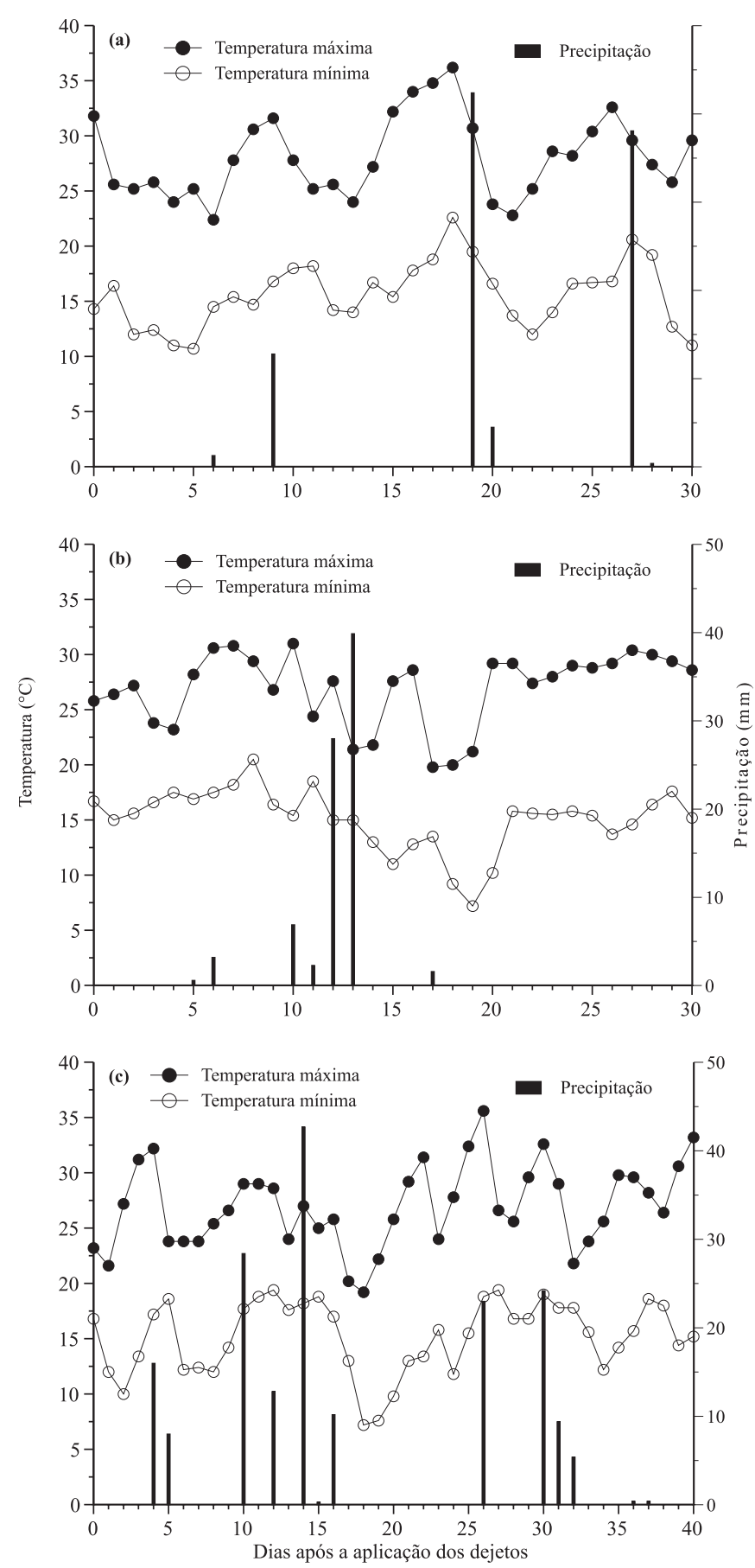

Figura 1. Temperaturas mínimas e máximas diárias e precipitação diária ocorridas após a aplicação das doses 40 e $80 \mathrm{~m}^{3}$ ha $^{-1}$ de dejetos líquidos de suínos, sobre os resíduos culturais dos sistemas aveia/milho e pousio/milho, em 1998 (a), 1999 (b) e 2000 (c).
O delineamento experimental foi o de blocos ao acaso, com parcelas subdivididas e três repetições. As parcelas principais, com dimensões de $5 \mathrm{~m}$ de largura por $15 \mathrm{~m}$ de comprimento, demarcadas em maio de 1998 , foram compostas por dois sistemas de cultura: aveia preta/milho e pousio/milho. Em outubro de 1998, 1999 e 2000, as parcelas principais foram divididas em três subparcelas de $5 \times 5 \mathrm{~m}$, nas quais foram aplicadas doses de dejetos de suínos (0, 40 e $80 \mathrm{~m}^{3} \mathrm{ha}^{-1}$ por ano), imediatamente antes da semeadura da cultura do milho. Os dejetos foram aplicados anualmente nas mesmas subparcelas, com auxílio de baldes.

Os dejetos de suínos foram obtidos em granja com animais de maternidade e recria, criados em regime de confinamento total. Os dejetos eram compostos pela mistura de fezes e urina dos animais, de outros materiais provenientes do processo criatório (água desperdiçada nos bebedouros, água de higienização, restos de alimentos, pêlos e poeira), além da água das chuvas.

A caracterização física e química dos dejetos foi realizada em 4 amostras, coletadas no momento da aplicação do material orgânico no campo. Essas amostras foram armazenadas durante 24 horas em refrigerador (em torno de $4^{\circ} \mathrm{C}$ ), até iniciarem-se as análises laboratoriais.

Os teores de $\mathrm{N}$ total e $\mathrm{N}$ amoniacal $\left(\mathrm{N}-\mathrm{NH}_{3}+\mathrm{N}-\mathrm{NH}_{4}{ }^{+}\right)$ foram determinados sem a secagem prévia dos dejetos, isto é, na forma em que os mesmos foram aplicados no campo. Em razão das dificuldades metodológicas para a obtenção de uma amostra representativa dos dejetos, a análise dos teores de $\mathrm{N}$ total e de $\mathrm{N}$ amoniacal do material foi efetuada após a separação das frações líquida e pastosa (Scherer et al., 1996). Após a separação das frações sólida (pastosa) e líquida, foi calculada a proporção entre elas. Tanto na análise do $\mathrm{N}$ total, como do $\mathrm{N}_{-} \mathrm{NH}_{4}{ }^{+}$, procedeu-se, inicialmente, à pesagem de aproximadamente $0,2 \mathrm{~g}$ da fração pastosa, a qual foi colocada em tubos de digestão. Com base na proporção entre as duas frações, separadas por centrifugação, foi adicionado, com pipeta, um volume de fração líquida, de forma a reconstituir a proporção em que as duas frações se encontravam originalmente nos dejetos.

Para a análise do $\mathrm{N}$ total, foi realizada a digestão das amostras, por via úmida, conforme Tedesco et al. (1995), porém, sem o uso de água oxigenada, já que testes preliminares indicaram que esse reagente provoca a evolução do material para fora dos tubos, durante a digestão. Após a digestão, as amostras receberam $\mathrm{NaOH}$ 
$10 \mathrm{~mol} \mathrm{~L}^{-1} \mathrm{e}$ foram destiladas em destilador de arraste de vapores semi-micro Kjeldahl. O N amoniacal dos dejetos foi determinado por destilação, após a adição de $20 \mathrm{~mL}$ de água destilada e óxido de magnésio.

A matéria seca foi determinada em amostras de aproximadamente $50 \mathrm{~g}$ de dejetos, em copos de béquer, os quais foram submetidos à secagem em estufa a $65^{\circ} \mathrm{C}$, até massa constante. $\mathrm{O} \mathrm{pH}$ foi medido diretamente em potenciômetro, em uma alíquota de aproximadamente $50 \mathrm{~mL}$ de dejetos. O teor de carbono orgânico dos dejetos foi determinado por via úmida, no material seco a $65^{\circ} \mathrm{C}$ e moído, conforme metodologia descrita por Tedesco et al. (1995). A composição física e química dos dejetos, utilizados nos três anos do presente estudo, encontra-se na Tabela 1.

Para se avaliar a nitrificação do $\mathrm{N}$ amoniacal dos dejetos, foram determinados os teores de $\mathrm{N}$ mineral em diversas épocas, após a aplicação dos dejetos $(5,10,20$ e 30 dias, em 1998; 1, 6, 17 e 29 dias, em 1999; 0, 5, 11, 21 e 36 dias, em 2000), nas camadas $0-5 ; 5-15 ; 15-30$ e 30-60 cm do solo, em amostras coletadas por meio de um trado calador. No primeiro ano, as coletas foram efetuadas em quatro pontos, distribuídos aleatoriamente dentro de cada parcela. Em razão da grande variabilidade nos teores de $\mathrm{N}$ mineral nas camadas superficiais, nas primeiras amostragens, nos dois últimos anos o número de pontos amostrados em cada parcela aumentou para oito, nas três primeiras datas de coleta. As subamostras foram misturadas, para constituir uma amostra composta, que foi acondicionada em sacos de plástico e mantida em congelador, a $-20^{\circ} \mathrm{C}$, até a execução das análises.

As coletas de amostras de solo, em cada ano, foram realizadas até o momento em que os teores de $\mathrm{N}-\mathrm{NH}_{4}{ }^{+}$, nos tratamentos com dejetos, diminuíram para valores

Tabela 1. Matéria seca e algumas características químicas dos dejetos líquidos de suínos, aplicados sobre os resíduos culturais nos sistemas aveia/milho e pousio/milho, em 1998, 1999 e 2000.

\begin{tabular}{lrrr}
\hline Componente & \multicolumn{3}{c}{ Ano } \\
\cline { 2 - 4 } & 1998 & 1999 & 2000 \\
\hline $\mathrm{N}$ total $\left(\mathrm{kg} \mathrm{m}^{-3}\right)$ & 3,58 & 2,45 & 3,10 \\
$\mathrm{~N}$ amoniacal $\left(\mathrm{kg} \mathrm{m}^{-3}\right)$ & 2,00 & 1,14 & 1,73 \\
$\mathrm{~N}$ amoniacal $\left(\% \mathrm{do} \mathrm{N}^{-} \mathrm{Notal}\right)$ & 55,90 & 46,50 & 55,80 \\
$\mathrm{~N}$ orgânico $\left(\mathrm{kg} \mathrm{m}^{-3}\right)$ & 1,58 & 1,31 & 1,37 \\
Matéria seca $\left(\mathrm{g} \mathrm{kg}^{-1}\right)$ & 58,20 & 37,80 & 50,20 \\
pH & 6,40 & 7,40 & 7,48 \\
Relação C/N & 5,40 & 5,25 & 4,38 \\
\hline
\end{tabular}

próximos aos dos tratamentos sem dejetos. Considerou-se, também, que nesse período inicial a absorção de $\mathrm{N}$ mineral do solo pelo milho foi mínima, em função da pequena produção de fitomassa da cultura e, também, em função de as amostras de solo terem sido coletadas entre as fileiras de milho.

Por ocasião da análise do $\mathrm{N}$ mineral, as amostras foram descongeladas, mantidas à temperatura ambiente e homogeneizadas manualmente. O N mineral foi extraído das amostras de solo úmido, tendo-se utilizado uma relação solo:solução extratora $\left(\mathrm{KCl} 1 \mathrm{~mol} \mathrm{~L}^{-1}\right)$ de 1:4. Após a extração, adicionou-se $0,2 \mathrm{~g}$ de $\mathrm{MgO}$ em uma alíquota de $20 \mathrm{~mL}$ do sobrenadante; procedeu-se, a seguir, à destilação em destilador semi-micro Kjeldahl, para a determinação de $\mathrm{N}-\mathrm{NH}_{4}{ }^{+}$. Após a adição de $0,2 \mathrm{~g}$ de liga de Devarda, procedeu-se à nova destilação do mesmo extrato, para a determinação de $\mathrm{N}^{-\mathrm{NO}_{2}{ }^{-}+}$ $\mathrm{N}-\mathrm{NO}_{3}{ }^{-}$(Tedesco et al., 1995). Em todas as avaliações, considerou-se que a totalidade do $\mathrm{N}$ mineral não amoniacal estava presente como nitrato, já que a metodologia de análise empregada não permite separar nitrato de nitrito. Além disso, os teores de $\mathrm{N}^{-\mathrm{NO}_{2}}{ }^{-}$do solo são normalmente baixos.

Paralelamente à determinação do $\mathrm{N}$ mineral, foi avaliada a umidade das amostras do solo, em estufa a $105^{\circ} \mathrm{C}$, durante 72 horas, para a apresentação dos resultados em base seca. As quantidades de $\mathrm{N}^{-\mathrm{NH}_{4}}{ }^{+} \mathrm{e}$ $\mathrm{N}-\mathrm{NO}_{3}{ }^{-}$foram expressas em quilograma por hectare, tendo-se considerado a concentração destas formas de $\mathrm{N}$ e a densidade do solo em cada camada.

A taxa de nitrificação foi estimada apenas para a camada $0-5 \mathrm{~cm}$ e para os períodos compreendidos entre 5 e 10,1 e 6 , e 0 e 5 dias após a aplicação dos dejetos, em 1998, 1999 e 2000, respectivamente, tendo-se assumido que nos primeiros dias após a aplicação dos dejetos tenha ocorrido apenas o acúmulo de $\mathrm{NO}_{3}{ }^{-}$no solo, sem perda ou consumo significativos de $\mathrm{NO}_{3}{ }^{-}$por lixiviação, imobilização, desnitrificação e redução dissimilatória de $\mathrm{NO}_{3}{ }^{-}$para $\mathrm{NH}_{4}{ }^{+}$. Para o cálculo das taxas líquidas de nitrificação ( $\mathrm{kg} \mathrm{ha}^{-1} \mathrm{dia}^{-1}$ de $\mathrm{N}^{-\mathrm{NO}_{3}}{ }^{-}$), em cada período, utilizouse a seguinte equação: taxa líquida de nitrificação $=(A-B) / t$, em que $A$ e $B$ são, respectivamente, a diferença na quantidade de $\mathrm{N}-\mathrm{NO}_{3}{ }^{-}\left(\mathrm{kg} \mathrm{ha}^{-1}\right)$ entre os tratamentos com e sem dejetos, na primeira e segunda datas de coleta em cada ano, e t é o tempo (dias) entre as duas datas. A diferença entre A e B representa a quantidade de $\mathrm{N}-\mathrm{NO}_{3}{ }^{-}$proveniente da oxidação biológica do 
$\mathrm{N}-\mathrm{NH}_{4}{ }^{+}$dos dejetos. A divisão dessa quantidade de $\mathrm{N}-\mathrm{NO}_{3}{ }^{-}$, pelo período de tempo decorrido entre as duas datas, resulta nas taxas líquidas de nitrificação.

A partir dos teores de $\mathrm{N}$ mineral, determinados em cada camada de solo, calculou-se a variação temporal da proporção entre as formas amoniacal e nítrica no solo, que fornece informação sobre a rapidez com que o processo de nitrificação ocorreu. Para este cálculo, considerou-se a soma das quantidades de $\mathrm{N}_{-} \mathrm{NH}_{4}{ }^{+}$e de $\mathrm{N}-\mathrm{NO}_{3}{ }^{-}$das quatro camadas de solo analisadas, já que, durante o período de avaliação, em cada ano, houve migração de nitrato no perfil do solo na camada $0-60 \mathrm{~cm}$.

Os resultados foram submetidos à análise da variância, e as médias foram comparadas pelo teste de Tukey, a 5\% de probabilidade.

\section{Resultados e Discussão}

Não houve interação significativa entre os fatores doses de dejetos (40 e $80 \mathrm{~m}^{3} \mathrm{ha}^{-1}$ ) e sistemas de cultura (pousio/milho e aveia/milho) quanto à taxa de nitrificação; houve apenas efeito isolado de cada fator (Tabela 2). Na média dos três anos, a taxa de nitrificação com a dose de $80 \mathrm{~m}^{3} \mathrm{ha}^{-1}$ superou a relativa à dose de $40 \mathrm{~m}^{3} \mathrm{ha}^{-1} \mathrm{em} 188 \%$. Este resultado confirma os obtidos em laboratório por Flowers \& O'Callaghan (1983), em que a taxa de nitrificação aumentou de 5,32 para 9,87 $\mathrm{mg} \mathrm{kg}^{-1}$ de solo $\mathrm{dia}^{-1}$ de

Tabela 2. Nitrificação líquida na camada de $0-5 \mathrm{~cm}$ do solo, nos primeiros cinco dias, com a aplicação de 40 e $80 \mathrm{~m}^{3} \mathrm{ha}^{-1}$ de dejetos líquidos de suínos, sobre os resíduos culturais dos sistemas aveia/milho e pousio (vegetação espontânea)/ milho, em 1998, 1999 e 2000(1).

\begin{tabular}{|c|c|c|c|c|}
\hline \multirow[t]{2}{*}{ Ano } & \multicolumn{2}{|c|}{ Sistemas de cultura } & \multicolumn{2}{|c|}{$\begin{array}{l}\text { Doses de dejetos } \\
\qquad\left(\mathrm{m}^{3} \mathrm{ha}^{-1}\right)\end{array}$} \\
\hline & Pousio/milho & Aveia/milho & 40 & 80 \\
\hline & \multicolumn{4}{|c|}{ Nitrificação líquida $\left(\mathrm{kg} \mathrm{ha}^{-1}\right)^{(2)}$} \\
\hline 1998 & $14,0 \mathrm{~b}$ & $28,9 \mathrm{a}$ & $8,7 \mathrm{~B}$ & $28,9 \mathrm{~A}$ \\
\hline 1999 & $18,7^{\mathrm{ns}}$ & 20,2 & $9,0 \mathrm{~B}$ & $29,9 \mathrm{~A}$ \\
\hline \multirow[t]{2}{*}{2000} & $17,3 b$ & $22,8 \mathrm{a}$ & $12,2 \mathrm{~B}$ & $27,3 \mathrm{~A}$ \\
\hline & \multicolumn{4}{|c|}{$\begin{array}{l}\text { Taxa líquida de nitrificação } \\
\left(\mathrm{kg} \mathrm{ha}^{-1} \text { dia }^{-1} \text { de }-\mathrm{NO}_{3}^{-}\right)\end{array}$} \\
\hline 1998 & $2,80 \mathrm{~b}$ & $5,77 \mathrm{a}$ & $1,73 \mathrm{~B}$ & $5,77 \mathrm{~A}$ \\
\hline 1999 & $3,74^{\mathrm{ns}}$ & 4,03 & $1,80 \mathrm{~B}$ & $5,97 \mathrm{~A}$ \\
\hline 2000 & $3,45 b$ & $4,55 \mathrm{a}$ & $2,44 \mathrm{~B}$ & $5,46 \mathrm{~A}$ \\
\hline
\end{tabular}

${ }^{(1)}$ Médias na linha seguidas por letras iguais, minúsculas nos sistemas de culturas e maiúsculas nas doses de dejeto, não diferem entre si pelo teste de Tukey, a $5 \%$ de probabilidade. nsNão-significativo. ${ }^{(2)}$ Representa a diferença na quantidade de $\mathrm{N}-\mathrm{NO}_{3}{ }^{-}\left(\mathrm{kg} \mathrm{ha}^{-1}\right)$ entre os tratamentos com e sem dejetos nas duas primeiras datas de coleta de solo em cada ano.
$\mathrm{N}-\mathrm{NO}_{3}{ }^{-}$, quando a quantidade de $\mathrm{N}$ aplicada com dejetos líquidos de suínos aumentou de 50 para $250 \mathrm{mg} \mathrm{kg}^{-1}$ de solo de $\mathrm{N}-\mathrm{NH}_{4}{ }^{+}$. Esse efeito foi atribuído ao aumento do $\mathrm{pH}$ do solo, proporcionado pelos dejetos, para níveis mais adequados à nitrificação autotrófica e, também, à presença de microrganismos heterotróficos nos dejetos, os quais podem oxidar $\mathrm{O} \mathrm{NH}_{4}{ }^{+}$a $\mathrm{NO}_{2}^{-}$(Flowers \& O'Callaghan, 1983).

Quanto ao efeito dos sistemas de cultura sobre a taxa líquida de nitrificação, observa-se, na Tabela 2, que a aplicação dos dejetos sobre os resíduos culturais do sistema aveia/milho resultou em maiores taxas de nitrificação na camada $0-5 \mathrm{~cm}$ do que no sistema pousio/milho, com diferenças significativas em dois dos anos avaliados. A diferença média na taxa de nitrificação, em favor do sistema aveia/milho, foi de $1,45 \mathrm{~kg} \mathrm{ha}^{-1}$ de $\mathrm{N}^{-\mathrm{NO}_{3}}{ }^{-}$por dia (43\%). A maior taxa de nitrificação no sistema aveia/milho se deve, provavelmente, ao fato de que nesse sistema havia maior quantidade de resíduos culturais na superfície do solo do que no sistema pousio/ milho, o que contribuiu para a manutenção de condições iniciais de umidade do solo mais favoráveis à oxidação microbiana do $\mathrm{N}^{-\mathrm{NH}_{4}}{ }_{4}$. Tais resultados evidenciam a relação entre a presença de resíduos culturais na superfície e a umidade do solo e a sua influência na velocidade de nitrificação do $\mathrm{N}$ amoniacal aplicado ao solo.

A quantificação da velocidade de nitrificação, bem como da cinética desse processo, exige que a determinação na variação das concentrações de $\mathrm{N}$ amoniacal e nítrico no solo seja feita freqüentemente, principalmente nos períodos iniciais após a aplicação dos dejetos, durante a fase ativa de oxidação do $\mathrm{NH}_{4}{ }^{+}$a $\mathrm{NO}_{3}{ }^{-}$. Em razão do volume de trabalho imposto por essa exigência, existem poucos resultados de pesquisa em que a nitrificação com a aplicação de dejetos de suínos tenha sido determinada em condições de campo. No Canadá, à temperatura média de $11^{\circ} \mathrm{C}$ (com extremos de 1 a $25^{\circ} \mathrm{C}$ ), Rochette et al. (2001) aplicaram a dose de $74 \mathrm{~m}^{3} \mathrm{ha}^{-1}\left(150,2 \mathrm{~kg} \mathrm{ha}^{-1}\right.$ de N-NH$\left.{ }_{4}^{+}\right)$de dejetos líquidos de suínos, sobre os resíduos culturais de canola, e mediram diariamente os teores de $\mathrm{N}$ mineral no solo, durante os primeiros 11 dias após a aplicação dos dejetos. A produção e acúmulo de $\mathrm{N}_{-} \mathrm{NO}_{3}{ }^{-}$, avaliados na camada de $0-5 \mathrm{~cm}$ do solo, somente se iniciaram 50 horas após a aplicação de dejetos, o que indica a ocorrência de uma fase de latência no processo de nitrificação relacionada, principalmente, ao período requerido para a síntese de enzimas durante o crescimento inicial da população de 
bactérias nitrificadoras (Malhi \& McGill, 1982). No presente trabalho, este aspecto não pôde ser avaliado, pois as determinações de $\mathrm{N}$ mineral somente foram realizadas nos primeiros cinco e seis dias após a aplicação dos dejetos, em 1999 e 2000, respectivamente, e entre cinco e dez dias, em 1998.

Os valores estimados para as taxas de nitrificação do $\mathrm{N}$ amoniacal aplicado ao solo com os dejetos, a partir do

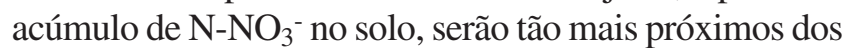
valores reais quanto menor tenha sido, durante o período de avaliação, a intensidade dos processos que resultam no desaparecimento e no consumo de $\mathrm{N}^{-} \mathrm{NO}_{3}{ }^{-}$: lixiviação, imobilização, desnitrificação e redução dissimilatória do $\mathrm{N}-\mathrm{NO}_{3}{ }^{-}$para $\mathrm{N}-\mathrm{NH}_{4}{ }^{+}$. Pode-se considerar que esses processos tenham sido nulos ou de baixa intensidade. Isto porque, logo após a aplicação dos dejetos, a forma predominante de $\mathrm{N}$ mineral é a amoniacal e, na presença de $\mathrm{N}_{-} \mathrm{NO}_{3}{ }^{-}$e $\mathrm{N}-\mathrm{NH}_{4}{ }^{+}$, os microrganismos heterotróficos assimilam, preferencialmente, a forma amoniacal, como demonstraram Recous et al. (1992). Em nenhum dos anos deste estudo, houve, nos primeiros dias após a aplicação dos dejetos, a ocorrência de chuvas (Figura 1), em quantidade que pudesse ter provocado a perda de $\mathrm{NO}_{3}{ }^{-}$ por lixiviação, para além da camada de solo avaliada. É provável que as condições iniciais, predominantemente aeróbicas, não tenham proporcionado perdas significativas de $\mathrm{NO}_{3}{ }^{-}$por desnitrificação e nem a transformação do $\mathrm{NO}_{3}{ }^{-}$em $\mathrm{NH}_{4}{ }^{+}$por redução dissimilatória, já que este processo somente ocorre em ambientes altamente reduzidos (Fazzolari et al., 1990).

No trabalho de Rochette et al. (2001), realizado no Canadá, em um solo com $27 \%$ de argila e com a aplicação dos dejetos líquidos de suínos sobre os resíduos culturais de canola, na fase de nitrificação ativa (50 a 150 horas após a aplicação dos dejetos), a acumulação líquida de $\mathrm{N}^{-\mathrm{NO}_{3}}{ }^{-}$, na camada de $0-5 \mathrm{~cm}$ do solo, atingiu cerca de $17,6 \mathrm{~kg} \mathrm{ha}^{-1}$ de $\mathrm{N}^{-N^{-}}{ }_{3}^{-}$, o que resultou numa taxa de nitrificação líquida de $4,2 \mathrm{~kg} \mathrm{ha}^{-1} \mathrm{dia}^{-1}$ de $\mathrm{N}^{-} \mathrm{NO}_{3}^{-}$ para o período considerado. Esse valor é relativamente próximo àqueles encontrados no presente trabalho para a aplicação dos dejetos sobre os resíduos culturais de aveia/milho, na média das duas doses de dejetos (Tabela 2). Na dose de $80 \mathrm{~m}^{3} \mathrm{ha}^{-1}$ de dejetos, em que a quantidade de $\mathrm{N}^{-\mathrm{NH}_{4}}{ }^{+}$aplicada variou de $160 \mathrm{~kg} \mathrm{ha}^{-1}$ em 1998 a $91 \mathrm{~kg} \mathrm{ha}^{-1}$ em 1999, a taxa média de nitrificação de $5,73 \mathrm{~kg} \mathrm{ha}^{-1} \mathrm{dia}^{-1}$ de $\mathrm{N}^{-} \mathrm{NO}_{3}{ }^{-}$é $36 \%$ superior àquela encontrada por Rochette et al. (2001). Tais diferenças podem ser atribuídas, principalmente, às condições de solo e de clima de cada local. Todavia, as taxas de nitrificação encontradas evidenciam que o $\mathrm{N}-\mathrm{NH}_{4}{ }^{+}$aplicado com os dejetos é rapidamente oxidado a $\mathrm{N}-\mathrm{NO}_{3}-$ no solo, mesmo quando os dejetos são distribuídos sobre resíduos culturais no sistema plantio direto, como foi o caso do presente trabalho.

A variação temporal da proporção entre as formas amoniacal e nítrica no solo, apresentada na Figura 2, evidencia que o $\mathrm{N}$ amoniacal dos dejetos foi rapidamente nitrificado e confirma as elevadas taxas de nitrificação estimadas para os primeiros dias após a aplicação dos dejetos (Tabela 2). Nos três anos, o $\mathrm{N}^{-\mathrm{NH}_{4}}{ }^{+}$foi praticamente todo oxidado a $\mathrm{N}-\mathrm{NO}_{3}{ }^{-}$, entre 15 e 20 dias após a aplicação dos dejetos, pois, a partir desta data, a proporção da forma amoniacal em relação à forma nítrica foi muito baixa. Estes resultados coincidem com os de Morvan (1999) em um estudo de incubação em laboratório, a $16^{\circ} \mathrm{C}$, onde, para dois dos três solos avaliados, o N-NH${ }_{4}^{+}$de 30 diferentes amostras de dejetos líquidos de suínos foi completamente nitrificado em 24 dias. Todavia, para um dos solos estudados por esse autor, ainda havia teores elevados de $\mathrm{N}_{-} \mathrm{NH}_{4}{ }^{+}$ ao final do experimento. Este fato, aliado à grande variabilidade das taxas de nitrificação, verificadas entre os solos estudados, levou o autor à conclusão de que o potencial de nitrificação varia de acordo com o tipo de solo.

Outro resultado a destacar na Figura 2 é o de que, com a aplicação dos dejetos sobre os resíduos culturais do sistema pousio/milho, o aumento na proporção de $\mathrm{N}-\mathrm{NO}_{3}{ }^{-}$ocorreu de forma mais gradual do que no sistema aveia/milho. Provavelmente, o efeito positivo dos resíduos culturais na manutenção da umidade do solo, especialmente nas camadas superficiais, também condicionou este resultado.

A rapidez com que o $\mathrm{N}-\mathrm{NH}_{4}{ }^{+}$dos dejetos foi oxidado para $\mathrm{N}-\mathrm{NO}_{3}{ }^{-}$pode ter duas conseqüências importantes, do ponto de vista de disponibilidade de $\mathrm{N}$ no solo e da poluição ambiental: na fase inicial de desenvolvimento das culturas comerciais, quando a absorção de $\mathrm{N}$ é muito pequena, se houver drenagem de água no perfil do solo, o risco de lixiviação de $\mathrm{N}-\mathrm{NO}_{3}{ }^{-}$é aumentado, já que a intensidade desse processo depende do volume de água drenado e da concentração de $\mathrm{N}^{-\mathrm{NO}_{3}}{ }^{-}$na solução do solo (Díez et al., 2004); se ocorrer a lixiviação conjunta do $\mathrm{N}-\mathrm{NO}_{3}{ }^{-}$produzido e do carbono orgânico solúvel em água, presente tanto nos resíduos culturais como nos dejetos, podem aumentar as perdas de $\mathrm{N}$ por desnitrificação (Rochette et al., 2004), pois as 
bactérias que realizam este processo são heterotróficas. Além de servir como fonte de energia às bactérias desnitrificadoras, a fração orgânica mais facilmente decomponível dos resíduos culturais e dos dejetos pode ser rapidamente oxidada pela população microbiana heterotrófica, aumentando o consumo de
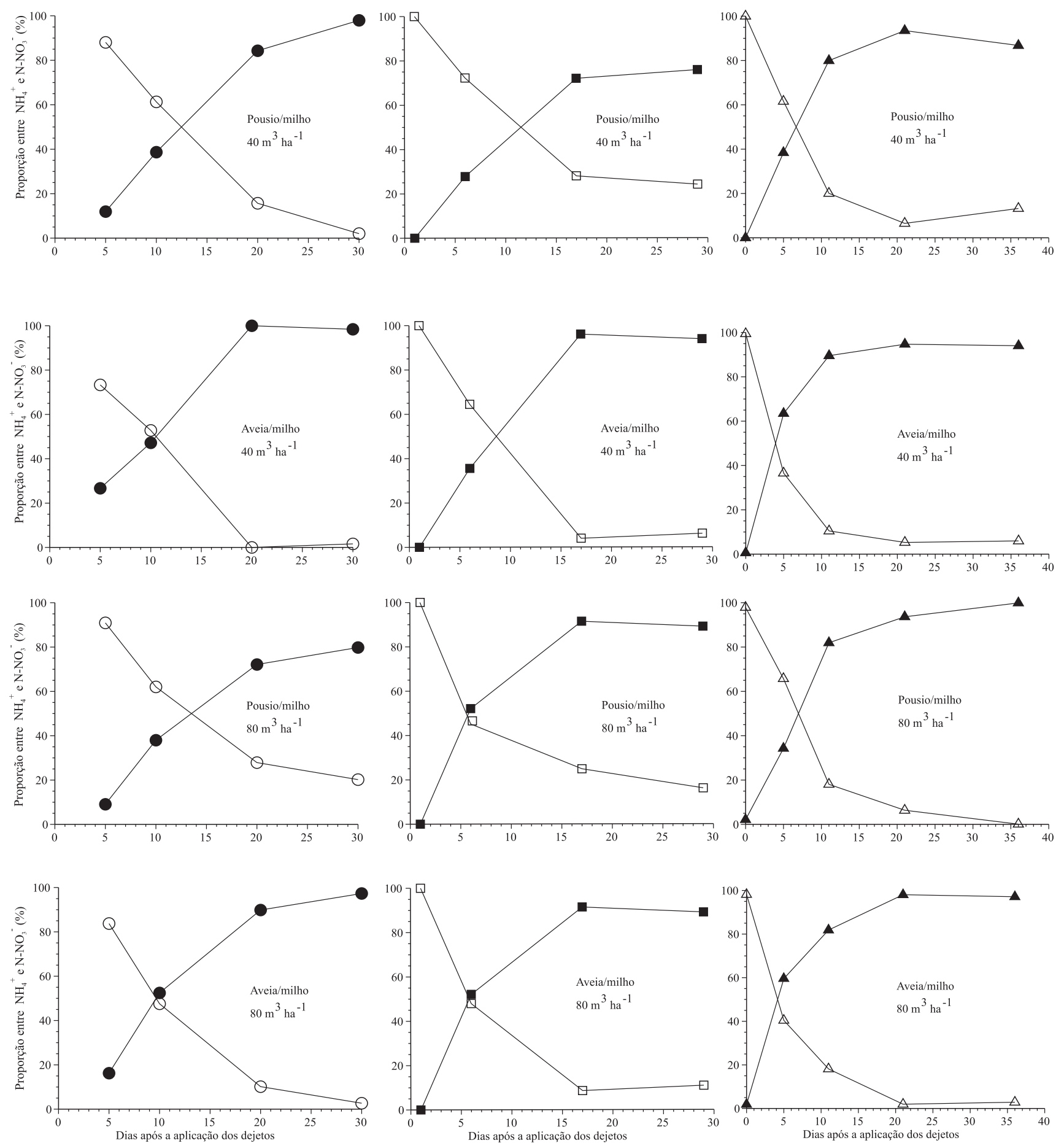

Figura 2. Variação temporal na proporção entre $\mathrm{N}_{-} \mathrm{NH}_{4}{ }^{+}(\mathrm{O}, \square, \Delta)$ e $\mathrm{N}_{-} \mathrm{NO}_{3}^{-}(\mathbf{\bullet}, \mathbf{\square}, \mathbf{\Delta})$, na camada de $0-60 \mathrm{~cm}$ do solo (soma das camadas 0-5, 5-15, 15-30 e 30-60 cm), nos primeiros 36 dias após a aplicação das doses 40 e $80 \mathrm{~m}^{3}$ ha-1 de dejetos líquidos de suínos, sobre os resíduos culturais dos sistemas aveia/milho e pousio/milho, em 1998 (círculo), 1999 (quadrado) e 2000 (triângulo). 
$\mathrm{O}_{2}$ e criando zonas do perfil do solo com baixo potencial redox, condição essencial à desnitrificação (Dendooven et al., 1998).

Observou-se, neste trabalho, que o $\mathrm{N}$ amoniacal dos dejetos é rapidamente nitrificado, mesmo sem a sua incorporação ao solo. O aparecimento precoce de $\mathrm{N}-\mathrm{NO}_{3}{ }^{-}$no solo, quando ainda não há uma cultura para absorvê-lo, o torna mais suscetível a perdas por lixiviação e desnitrificação, dependendo das condições ambientais. Duas estratégias parecem promissoras, para diminuir as consequiências negativas do uso de dejetos resultantes das elevadas taxas de nitrificação do $\mathrm{N}$ amoniacal, tanto do ponto de vista ambiental, como do aproveitamento do $\mathrm{N}$ pelas culturas. Uma envolve a aplicação parcelada dos dejetos em duas épocas: na implantação das culturas e em cobertura. Com isso, o $\mathrm{N}-\mathrm{NO}_{3}{ }^{-}$produzido pelas bactérias nitrificadoras pode ser mais eficientemente absorvido pelas culturas. A outra envolve o uso de inibidores de nitrificação, juntamente com a aplicação dos dejetos ao solo (Whitehead, 1995; Klein et al., 1996).

\section{Conclusões}

1. O N amoniacal dos dejetos líquidos de suínos é rapidamente nitrificado no solo em plantio direto e completamente oxidado a $\mathrm{N}$ nítrico, entre 15 e 20 dias após a aplicação dos dejetos.

2. A nitrificação aumenta com a quantidade de $\mathrm{N}$ amoniacal aplicada com os dejetos.

3. As taxas líquidas de nitrificação, em plantio direto, são maiores com a aplicação dos dejetos líquidos de suínos sobre os resíduos culturais de aveia/milho do que sobre pousio/milho.

\section{Referências}

DENDOOVEN, L.; BONHOMME, E.; MERCKX, R.; VLASSAK, $\mathrm{K}$. Injection of pig slurry and its effects on the dynamics of nitrogen and carbon in a loamy soil under laboratory conditions. Biology and Fertility of Soils, v.27, p.5-8, 1998.

DÍEZ, J.A.; HERNAIZ, P.; MUÑOZ, M.J.; TORRE, A. de la; VALLEJO, A. Impact of pig slurry on soil properties, water salinization, nitrate leaching and crop yield in a four-year experiment in Central Spain. Soil Use and Management, v.20, p.444-450, 2004.
EMBRAPA. Centro Nacional de Pesquisa de Solos (Rio de Janeiro, RJ). Sistema brasileiro de classificação de solos. Brasília: Embrapa-SPI/Embrapa-CNPS, 1999. 412p.

FAZZOLARI, E.; MARIOTTI, A.; GERMON, J.C. Dissimilatory ammonia production vs. denitrification in vitro and in inoculated agricultural soil samples. Canadian Journal of Microbiology, v.36, p.786-793, 1990.

FLOWERS, T.H.; O'CALLAGHAN, J.R. Nitrification in soils incubated with pig slurry or ammonium sulphate. Soil Biology and Biochemistry, v.15, p.337-342, 1983.

KLEIN, C.A.M. de; LOGTESTIJN, R.S.P. van; MEER, H.G. van de; GEURINK, J.H. Nitrogen losses due to denitrification from cattle slurry injected into grassland soil with and without a nitrification inhibitor. Plant and Soil, v.183, p.161-170, 1996.

L'HIRONDEL, J.; L'HIRONDEL, J.L. Nitrate and man: toxic, harmless or beneficial. Wallingford: CAB International, 2002. 168p.

MALHI, S.S.; McGILL, W.B. Nitrification in three Alberta soils: effect of temperature, moisture and substrate concentration. Soil Biology and Biochemistry, v.14, p.393-399, 1982.

MORVAN, T. Quantification et modélisation des flux d'azote résultant de l'épandage de lisier. 1999. 157p. Tese (Doutorado) - Université Paris 6, Paris.

MÜLLER, C.; STEVENS, R.J.; LAUGHLIN, R.J. Evidence of carbon-stimulated $\mathrm{N}$ transformations in grassland soil after slurry application. Soil Biology and Biochemistry, v.35, p.285-293, 2003.

RECOUS, S.; MACHET, J.M.; MARY, B. The partitioning of fertilizer-N between soil and crop: comparison of ammonium and nitrate applications. Plant and Soil, v.144, p.101-111, 1992.

ROCHETTE, P.; ANGERS, D.A.; CHANTIGNY, M.H.; BERTRAND, N.; CÔTÉ, D. Carbon dioxide and nitrous oxide emissions following fall and spring applications of pig slurry to an agricultural soil. Soil Science Society of America Journal, v.68, p.1410-1420, 2004.

ROCHETTE, P.; CHANTIGNY, M.H.; ANGERS, D.A.; BERTRAND, N.; CÔTÉ, D. Ammonia volatilization and soil nitrogen dynamics following fall application of pig slurry on canola crop residues. Canadian Journal of Soil Science, v.81, p.515-523, 2001.

SCHERER, E.E.; AITA, C.; BALDISSERA, I.T. Avaliação da qualidade do esterco líquido de suínos da região oeste catarinense para fins de utilização como fertilizante. Florianópolis: Epagri, 1996. 46p. (Boletim técnico, 79).

SCHMIDT, E.L. Nitrification in soil. In: STEVENSON, F.J. (Ed.). Nitrogen in agricultural soils. Madison: American Society of Agronomy, 1982. p.253-288. (Agronomy, 22).

TEDESCO, M.J.; GIANELLO, C.; BISSANI, C.A.; BOHNEN, H.; VOLKWEISS, S.J. Análises de solo, plantas e outros materiais. Porto Alegre: UFRGS, 1995. 174p. (Boletim técnico, 5).

WHITEHEAD, D.C. Grassland nitrogen. Wallingford: CAB International, 1995. 352p.

Recebido em 16 de maio de 2006 e aprovado em 20 de outubro de 2006 